\title{
ESOFAGITE EOSINOFÍLICA: uma nova entidade que causa inflamação do tubo digestivo
}

DESCRITORES - Esofagite. Eosinofilia. Criança.

Inicialmente é necessário ressaltar a qualidade do artigo publicado ${ }^{(2)}$ neste número dos ARQUIVOS de GASTROENTEROLOGIA, onde dois grupos de pediatras gastroenterologistas se uniram para apresentar interessante e original série de casos de pacientes pediátricos brasileiros com esofagite eosinofílica que, ao que tudo indica, é uma nova entidade que causa inflamação no tubo digestivo.

Esofagite eosinofílica pode ser definida como uma entidade clínico-patológica primária do esôfago que se caracteriza por sintomas esofágicos ou do trato digestivo superior em associação com biopsia esofágica com mais de 15 eosinófilos/campo de grande aumento em um ou mais fragmentos na ausência de doença do refluxo gastroesofágico, descartada por pHmetria do esôfago terminal ou por falta de resposta terapia com dose elevada de inibidor de bomba de prótons ${ }^{(3)}$. Esta definição foi adotada por um grande grupo de associados da Amerian Gastroenterology Association (AGA) e da North American Society of Pediatric Gastroenterology, Hepatology and Nutrition (NASPGHN), que prepararam excelente texto de revisão sistemática e consenso ${ }^{(3)}$. Nesta definição foram necessárias algumas restrições para que fosse possível analisar criticamente as informações dos 120 artigos científicos selecionados.

No estudo de FERREIRA et al. ${ }^{(2)}$, o diagnóstico dos 29 pacientes pediátricos com esofagite eosinofílica foi confirmado pela presença de mais de 20 eosinófilos na biopsia do esôfago terminal, em um ou mais campos de grande aumento, sendo que as biopsias do antro gástrico e duodeno não apresentavam infiltração por eosinófilos. Este é um ponto importante que não foi considerado na definição apresentada acima que não exige exclusão de infiltração eosinofílica em outras partes do tubo digestivo. $\mathrm{Na}$ definição proposta pela AGA-NASPGHN ${ }^{(3)}$ inclui-se a exigência de $\mathrm{pHmetria} \mathrm{normal} \mathrm{e/ou} \mathrm{prova} \mathrm{terapêutica} \mathrm{com}$ omeprazol, no entanto, pode-se questionar se a doença do refluxo gastroesofágico e a esofagite eosinofílica não podem co-existir ou mesmo serem predisponentes uma da outra.

A ampla faixa etária do estudo de FERREIRA et al. ${ }^{(2)}$, entre 1 e 19 anos, permitiu que todo o espectro clínico da esofagite eosinofílica na faixa etária pediátrica fosse contemplado: anorexia, recusa para alimentação, regurgitações, vômitos e comprometimento nutricional nas crianças pequenas e nas crianças em idade escolar, e adolescentes quadro de disfagia e impactação de alimentos no esôfago. Os achados endoscópicos são bem característicos com a presença de estrias verticais, nódulos esbranquiçados, anéis circulares e evidência de estenose em alguns casos. Notar que endoscopia normal predominou nos menores de 6 anos $(42,9 \%, 6 / 14$ versus $6,7 \%, 1 / 15$ nos com mais de 6 anos; $P=0,035$, conforme dados da Tabela $1^{(2)}$ ). Nesta faixa etária, os sintomas podem ser inespecíficos e difíceis de analisar o que, em minha opinião, torna mais difícil o diagnóstico, aumentando sua dependência do achado histológico. Vale lembrar que a histologia além da infiltração de eosinófilos pode se acompanhar de microabscessos com eosinófilos, camada superficial de eosinófilos e hiperplasia da camada basal. Questão fundamental é qual o critério para contagem dos eosinófilos na biopsia esofágica. O maior número de eosinófilos nos diferentes campos de grande aumento (400 vezes) avaliados é o mais utilizado. No entanto, alguns estudos propõem que a contagem seja feita em vários ou todos os campos. Outro ponto importante é o local do esôfago onde foi obtida a biopsia, infiltração de eosinófilos no terço médio ou proximal do esôfago pode ter valor diagnóstico maior, especialmente, se não existir infiltração expressiva de eosinófilos no esôfago terminal. Aliás, eosinófilos podem ser encontrados normalmente na mucosa do esôfago? Reavaliação de espécimes considerados normais previamente, pertencentes a pacientes submetidos a biopsia do tubo digestivo por sintomas atribuídos no final da avaliação a distúrbios funcionais do sistemas digestório, mostrou eosinófilos em apenas 2,7\% dos campos examinados e contagem de 0,03 eosinófilos/campo, quantidade inferior à observada em outras partes do tubo digestivo ${ }^{(1)}$. A outra entidade prevalente, além da esofagite eosinofílica que pode ocasionar infiltração de eosinófilos no esôfago é a doença do refluxo gastroesofágico, mas geralmente, com menor número de células.

Vale ressaltar que não existem evidências de que a esofagite eosinofílica diminua a expectativa de vida. Não existem evidências de que as alterações histológicas possam evoluir para adenocarcinoma ${ }^{(3)}$. Estes pontos 
têm que ser apreciados considerando que existem poucas informações consistentes a respeito da história natural da esofagite eosinofílica.

Do ponto de vista prático, como conduzir, no presente momento, um paciente com esofagite eosinofílica. Acredito que as evidências da literatura indicam dois procedimentos terapêuticos básicos: 1. corticoterapia e 2. terapia dietética. A corticoterapia tópica pode ser feita com duas administrações diárias de fluticasona na cavidade oral, a ser deglutida, respeitando-se jejum oral de 30 a 60 minutos $^{(2,3)}$. Nos casos muito graves, corticoterapia sistêmica. Os efeitos colaterais da corticoterapia sistêmica são bem conhecidos e a tópica pode ter a candidíase como complicação. Na terapia dietética: nas crianças de baixa idade com comprometimentos do estado nutricional, considerar as fórmulas de aminoácidos como terapia inicial. Nas crianças maiores ou sem comprometimento nutricional, considerar a dieta de exclusão de seis alimentos com maior potencial alergênico (leite de vaca e derivados, trigo, soja, amendoim, ovo, peixe/frutos do mar) ${ }^{(4)}$.

Para finalizar, deve ser lembrado que ainda existem muitas lacunas no conhecimento sobre a esofagite eosinofílica que, entre outros, devem ser focos de novas investigações ${ }^{(3)}$ : 1. objetivo do tratamento - remissão dos sintomas com ou sem plena normalização histológica obrigatória; 2 . aprimoramento das propostas terapêuticas e normas para o acompanhamento clínico e endoscópico; 3 . identificação dos eventuais alérgenos alimentares envolvidos na etiologia da esofagite eosinofílica em determinado paciente, e 4 . conduta no paciente assintomático com infiltração de eosinófilos na mucosa esofágica.

Mauro Batista de MORAIS

\section{REFERÊNCIAS}

1. DeBrosse CW, Case JW, Putnam PE, Collins MH, Rothenberg ME. Quantity and distribution of eosinophils in the gastrointestinal tract of children. Pediatr Dev Pathol. 2006;9:210-8.

2. Ferreira CT, Vieira MC, Vieira SMG, Silva GS, Yamamoto DR, Silveira TR. Esofagite eosinofílica em 29 pacientes pediátricos. Arq Gastroenterol. 2008;45:141-6.
3. Furuta GT, Liacouras CA, Collins MH, Gupta SK, Justinich C, Putnam PE, Bonis P, Hassall E, Straumann A, Rothenberg ME. Eosinophilic esophagitis in children and adults: a systematic review and consensus recommendations for diagnosis and treatment. Gastroenterology. 2007;133:1342-63.

4. Kagalwalla AF, Sentongo TA, Ritz S, Hess T, Nelson SP, Emerick KM, Melin-Aldana $\mathrm{H}, \mathrm{Li}$ BU. Effect of six-food elimination diet on clinical and histologic outcomes in eosinophilic esophagitis. Clin Gastroenterol Hepatol. 2006;4:1097-102.

*Disciplina de Gastroenterologia Pediátrica da Universidade Federal de São Paulo (UNIFESP-EPM), São Paulo, SP. 